\title{
UNA HIPÓTESIS DE TRABAJO: TERMINA EL CONFLICTO, ESTALLA EL POSCONFLICTO ${ }^{1}$
}

\section{A HYPOTHESIS OF WORK: IT FINISHES THE CONFLICT, THE POSCONFLICTO EXPLODES}

\author{
Carlos Arturo Velandia Jagua ${ }^{2}$
}

Director de ABCPAZ

\section{Resumen}

El progreso de las negociaciones con las Farc deben integrar los diálogos con el Eln, de lo contrario el país se vería abocado a la prolongación del conflicto interno que podría incluir otras fuerzas contrarias a las negociaciones. Este artículo realiza un ejercicio de plantear varios escenarios hipotéticos de paz y también de guerra.

Palabras clave: conflicto interno, negociaciones de paz, Farc, Eln, fuerzas patrióticas de salvación nacional.

\section{Absctract}

The progress of the negotiations with the Farc they must integrate the dialogs with the Eln, otherwise the country would meet doomed to the prolongation of the internal conflict that might include other forces opposite to the negotiations. This article realizes an exercise of raising several hypothetical scenes of peace and also of war.

Keywords: internal conflict, negotiations of peace, Farc, Eln, patriotic forces of national salvation.

Recibido: 25 de noviembre de 2015

Aceptado: 15 de diciembre de 2015

Luego de más de 1.100 días de diálogos ininterrumpidos entre el Gobierno Nacional y las FARC-EP, en el propósito de poner punto final a la guerra, y dejar sentadas las bases para la ampliación y profundización de la democracia; como punto de partida para que la sociedad, sin exclusiones, construya la justicia social y la sostenibilidad de la paz, que garantice que nunca más el ejercicio de la política esté acompañada por la violencia; éste proceso ha alcanzado su madurez, pasando su punto de no retorno y encaminándose hacia su recta final, que será coronada con la firma del acuerdo de final del conflicto.

Pero frente a esta posibilidad que se vislumbra, se cierne sobre ella una inmensa sombra de incertidumbre, generada por el estado de empantanamiento e inmovilidad del proceso de exploración del Gobierno con la guerrilla del ELN, el cual no ha sido posible concluir, para que de inmediato se instale la Mesa de Diálogos en fase pública y así enrutarse hacia la terminación definitiva de la guerra, en el marco de un proceso de paz único y nacional.

1 Ponencia de la Quinta Cumbre Nacional por la Paz; también disponible en Blog Paréntesis: alternativa a la dictadura mediatíca: http://parentesiscali.blogspot.com.br/2016/03/ponencia-de-carlos-arturo-velandia-en.html.

2 Ex integrante del Eln. Director de ABCPAZ. Gestor de la salida negociada del conflicto. Investigador y analista del conflicto interno (en publicaciones como la revista Semana). Twitter: @carlosvelandiaj. El contenido del artículo es responsabilidad exclusiva de su autor, no representa el punto de vista de la Revista Desbordes. 
Honda preocupación genera en la sociedad, que mientras el Gobierno y las FARC-EP han desescalado la confrontación militar al punto de cero histórico, el Gobierno y el ELN han escalado progresivamente la confrontación a máximos históricos, llenando de razones a la sociedad para dudar de la real voluntad de paz de las partes (Gobierno y ELN), que más se esfuerzan en distanciarse, en momentos en que se requiere el cierre definitivo del conflicto armado.

Hoy podemos decir que estamos en un escenario hacia la paz definitiva con las FARC-EP, lo que no necesariamente significaría la paz en la totalidad del territorio nacional, por cuanto un actor como el ELN, tan relevante en el conflicto como en la construcción de la paz, se está quedando inmerso en la guerra.

Es por ello, deber de los colombianos desarrollar una estrategia que combine tres presiones positivas sobre las partes, para que de una vez por todas definan el escenario de una paz con todos, que pueda ser implementada y construida en todos los territorios de la nación; porque la oportunidad de paz que está en curso, no solo es una oportunidad para las partes del conflicto, es por sobre todo una oportunidad para que el país pueda superar, de manera definitiva, el conflicto armado interno que tantas desgarraduras, dolor y atraso ha producido a Colombia y sus gentes.

Estas tres presiones positivas son:

Primera: La sociedad colombiana conmina al Gobierno y al ELN a destrabar el diálogo y a concluir la fase exploratoria, en un único ciclo de conversaciones, para dar paso de inmediato a la instalación de la Mesa de Diálogos en fase pública.

Segunda: La Comunidad Internacional, y de manera específica, los países de la región invitan a las partes a instalar la Mesa de Diálogos, con la advertencia de que Colombia recibirá todo la solidaridad y apoyo para hacer la paz, pero tendrá cero apoyo para hacer la guerra; habida cuenta que la paz es una necesidad para la seguridad y la convivencia con los países fronterizos, además de ser soporte fundamental para la seguridad de las naciones, la sostenibilidad democrática y hacer de la UNASUR una Zona de Paz.

Tercera: Nuevos acuerdos de la Mesa de La Habana, por si mismos generarán una presión positiva, los cuales actuarán como estímulo para desatrancar los diálogos y para imprimir más dinamismo en un proceso entre el Gobierno Nacional y el ELN.

El anterior análisis resulta incompleto si no prevemos potenciales escenarios, en el, desarrollo de los diálogos y del conflicto, para evitar sorpresas y para valorar la necesidad de cuidar los espacios de paz que se construyen y para corregir caminos mal emprendidos en la dinámica de buscar la paz dialogada.

Es necesario advertir que la formulación de hipótesis no son la realidad, es un recurso académico que permite prefigurar posibles desarrollos o evoluciones de una situación, para por anticipado prever también posibles actuaciones frente a los mismos. Cuando la formulación de hipótesis responde a desarrollos de tendencias lógicas, son útiles en la búsqueda de salidas, pero cuando se hace desde el tremendismo, el fatalismo, la ingenuidad y el catastrofismo, se transita por las sendas de la ficción y de la inutilidad.

\section{Primer escenario: acuerdo de paz con las FARC-EP y no paz con el ELN}

- Acción concertada entre las dos guerrillas para que el proceso con FARC-EP sea un tester y ELN quede en la reserva, para un regreso por si no se dan bien las cosas. En este caso FARC-EP apoyaría con armas, logística, y recursos económicos, antes de la dejación de armas. 
- Acción no concertada entre las dos guerrillas, en este caso el ELN unilateralmente decide esperar, para observar la implementación de los acuerdos, porque para ellos la palabra del Gobierno tiene poco valor, habida cuenta de la tradición secular de hechos incumplidos por parte del Estado frente a los acuerdos con las comunidades. Lo que importa son "los hechos", más que las palabras y la firma de papeles, reitera el ELN.

- El ELN cuestiona los Acuerdos de La Habana, los que califica como los resultados de "la paz de Santos o la paz oligárquica" y decide buscar con otro gobierno un modelo de "paz popular".

- El giro a la derecha en América Latina es un escenario de amenaza para las luchas populares y revolucionarias, que frena el ímpetu del ELN para pactar la paz.

- El Gobierno decide implementar y consolidar los acuerdos alcanzados con FARC-EP y presionar al ELN por la vía militar a aceptar los Acuerdos de La Habana, porque considera que el ELN "enreda hasta un aplauso", la agenda es gaseosa e inasible y potencialmente el ELN podría ser una amenaza para la paz con FARC-EP.

- El Gobierno es presionado por sectores empresariales y militares para mantener un frente de guerra, que justifique continuar sosteniendo las Fuerzas Armadas y el aparato militar sin alteraciones, combinando así el discurso de la paz con el de la guerra en nombre de la seguridad nacional y la defensa de la democracia.

Segundo escenario: acuerdo de paz con FARC-EP, implementación de acuerdos y proceso con ELN en fase pública

- La Mesa con ELN es retardante porque FARC-EP decide esperar acuerdos con ELN para unificar acuerdo único.

- Los Acuerdos de La Habana son un acumulado para una paz única y nacional. El ELN asume los Acuerdos de La Habana como propios, luego de introducirles matizaciones o mejoras, se logra un diálogo ágil y dinámico y en menos de un ańo se tendría un acuerdo final. Los Acuerdos con las dos insurgencias se unificarían en una Mesa de Conciliación de Acuerdos. El Acuerdo Único será sometido a refrendación, mediante el mecanismo que se acuerde con las dos guerrillas. Fechas probables: 23 de marzo 2016 firma de acuerdo de cese el fuego bilateral con FARC-EP; 31 de Marzo instalación de Mesa con ELN en fase pública, e inicio de desescalamiento hacia cese el fuego bilateral; 31 de agosto firma de acuerdo final con FARC-EP, firma de cese el fuego bilateral con ELN, inicio de implementación de acuerdos y pedagogía para refrendación de acuerdos. 31 de diciembre firma de acuerdo final con ELN, inicio de implementación de acuerdos y proceso de unificación de acuerdos; 28 de febrero acuerdo único listo para refrendación; 30 de abril refrendación de acuerdo único.

\section{Tercer escenario: paz con FARC-EP y guerra con ELN}

- Los Acuerdos de La Habana se implementan en territorios donde solo están las FARC-EP y en territorios comunes existe implementación parcial o bloqueo.

- Milicias farianas defienden sus territorios y la implementación de sus acuerdos, hay confrontación militar con desventaja para bases sociales y políticas de FARC-EP.

- Gobierno declara terminado el conflicto armado interno y desata ofensiva generalizada contra ELN, a quien califica como fuerza terrorista y criminal. 
- FARC-EP y Gobierno avanzan en la implementación de los Acuerdos de paz, se efectúa la dejación física de armas por parte de FARC-EP, se generan mecanismos de seguridad para sus miembros y en sus territorios, con presencia de Fuerza Pública del Estado, y se transforma en movimiento político legal e institucional.

- El ELN agrupa sus fuerzas guerrilleras en 3 grandes frentes de guerra estratégicos, a saber:

- Frente de Guerra Estratégico del Nororiente que agrupa las fuerzas del Frente de Guerra Norte (Guajira, Cesar), Frente de Guerra Nororiental (Santander, Norte de Santander), Frente de Guerra Oriental (Arauca, Boyacá, Casanare) y las del Área Darío Ramírez Castro (Nordeste Antioqueño, Bajo Cauca Antioqueño, Sur de Bolívar). El 70\% de la fuerza global.

- Frente de Guerra Estratégico del Suroccidente que agrupa las fuerzas del Frente de Guerra Suroccidente (Cauca, Valle y Nariño) y Frente de Guerra Occidental (Chocó y Eje Cafetero). El $20 \%$ de la fuerza global.

- Frente de Guerra Estratégico Urbano que articula las fuerzas clandestinas urbanas de las ciudades de Bogotá, Medellín Cali, Barranquilla, Bucaramanga, Barrancabermeja y otras ciudades menores. El $10 \%$ de la fuerza global.

- Los Frentes de Guerra Estratégicos se complementarán con Fuerzas localizadas en territorios de transfrontera de Venezuela y Ecuador.

- Los Frentes de Guerra Estratégicos tendrán Mando Único centralizado.

- Las Fuerzas del ELN localizadas en el interior del país migrarán al Frente de Guerra Estratégico más próximo, igualmente, estos Frentes serán nutridos por pequeños grupos e individuos inconformes o desencantados provenientes del proceso de paz con las FARC-EP.

- El ELN implementará modalidades de guerra de guerrillas como forma fundamental, combinada con guerra de movimientos y defensa de territorios con fuerzas de Milicias Territoriales. Desarrollará la guerra revolucionaria integral con implantación y despliegue de Fuerzas de Comando Urbano en las ciudades.

- La intensificación del conflicto armado en la frontera, sumado a la agudización de la crisis política, institucional en Venezuela, enfrenta a los poderes ejecutivo y legislativo hasta llegar a un punto de ruptura institucional. Sectores de oposición a la revolución y al Gobierno exigen que FABV expulsen a guerrilleros del ELN de su territorio y los contengan en la frontera. Sectores radicales de la revolución bolivariana dentro de la sociedad y del Estado, apoyan al ELN con recursos y armas. Grupos armados venezolanos como las Fuerzas Bolivarianas de Liberación - FBL y los Colectivos Urbanos de defensa de la revolución como La Piedrita, los Tupamaros, Simón Bolívar, Carapaica, Alí Primera y Alexis Vive; en Caracas y otras ciudades del país, se coordinan con el ELN, en el marco de una lucha por la defensa de la revolución bolivariana.

- El Frente de Guerra Estratégico Suroccidental, establecerá su bastión en el Macizo Colombiano desde donde podrá irradiar sus acciones hacia los departamentos del Cauca, Valle, Chocó, Tolima, Huila, Nariño Putumayo y Caquetá.

- En la trans-frontera ecuatoriana, el ELN buscará apoyos entre las viejas militancias del Alfarismo (Alfaro Vive Carajo), entre los refugiados colombianos y entre sectores sociales radicales, desafectos a la "revolución ciudadana” liderada por el presidente Rafael Correa.

- El ELN modificará su estrategia y postulados originales, para proponer una estrategia de guerra revolucionaria trinacional, para la liberación nacional y social y la construcción del socialismo en la patria de Bolívar: la Gran Colombia.

- La guerra se regionaliza y Estados Unidos incrementa su presencia en Colombia a través de planes de cooperación y ayuda militar, así como con el fortalecimiento de bases militares en Colombia: 
Malambo, Apiay, Bahía Málaga y con el despliegue de la IV Flota en el Mar Caribe.

- Si el ELN logra hacerse fuerte, construye y consolida estos teatros de operaciones en los próximos tres años, puede ocurrir:

- Que estime que tiene altas posibilidades estratégicas para la victoria de la guerra revolucionaria, en este caso continuará con el esfuerzo militar, o

- Que estime que no tiene posibilidades estratégicas, pero que cuenta con una mejor correlación de fuerzas en el campo de batalla, en este caso buscará la solución negociada con el nuevo gobierno electo en el año 2022.

- Si el ELN es derrotado militarmente, terminará por aceptar los términos que le imponga el Gobierno.

- Si el ELN se divide, la parte mayoritaria buscará el diálogo y la negociación con el Gobierno y la parte minoritaria será derrotada por el Estado.

\section{Otra amenaza}

Un escenario que conviene advertir, lo constituye la potencial amenaza de sectores opuestos al proceso de paz que no acepten los acuerdos y decidan alzarse en armas, para confrontar al Gobierno, a quien consideran un traidor al país y a la Constitución, por "haber entregado el país a los terroristas". Estas fuerzas provendrían del latifundismo armado, que consideran los acuerdos de paz pactados con las FARC contrarios a sus intereses, y que se opondrán a su implementación. Con tales argumentos, soliviantados e inspirados en posiciones prohijadas desde el partido Centro Democrático, se constituirá un movimiento guerrillero con frentes territoriales, denominado Fuerzas Patrióticas parar la Salvación Nacional - FPSN, que operará en los territorios donde el paramilitarismo históricamente ha tenido desarrollos importantes, como en regiones de las sabanas de los departamentos de Bolívar, Sucre, Magdalena, Meta, Vichada y Casanare; y las regiones del Nordeste Antioqueño, Bajo Cauca y Sur de Bolívar. Para ello tendrían como avanzada los llamados Ejército Anti-restitución, los que se articulan con BACRIM que operan en los territorios.

La FPSN establecerán tres frentes de guerra: Frente de Guerra Norte, que agrupa las fuerzas de Córdoba, Magdalena, Sucre, Cesar y Guajira, Frente de Guerra Occidental, que agrupa las fuerzas de Antioquia, Chocó y Eje Cafetero, y el Frente de Guerra Oriental que agrupa las fuerzas de Meta, Vichada, y Casanare.

El alzamiento armado ejercerá presión sobre la institucionalidad local y departamental, utilizará métodos similares a los ya conocidos y desarrollados por el paramilitarismo, se enfrentará a las Fuerzas Armadas del Estado, logrará controlar algunos territorios, con la complicidad o aquiescencia de gobernabilidades locales afines, y desatará una guerra de exterminio hacia el movimiento popular y de izquierda revolucionaria surgida tras los acuerdos de paz.

Estas guerrillas de extrema derecha no buscan la toma del poder, levantarán el discurso de la unidad nacional contra el terrorismo, contra el castro-chavismo, y llamarán a formar un gobierno de salvación nacional que deponga los acuerdos de paz y retorne el país bajo el amparo de la Constitución Nacional de 1991.

Si este proyecto llegase a implantarse y consolidarse, luego de 5 o 6 años de operaciones, podría llamar al gobierno a diálogos, para un pacto político, a cambio de la dejación de armas.

El partido Centro Democrático y algunos medios de comunicación apoyarán a este movimiento, mediante la justificación, no lo reconocerán como propio, no asumirán responsabilidad alguna de sus acciones, pero estará presto a oxigenarlo política e ideológicamente desde su discurso político. 


\section{Fuerzas del ELN y territorios - 2016}

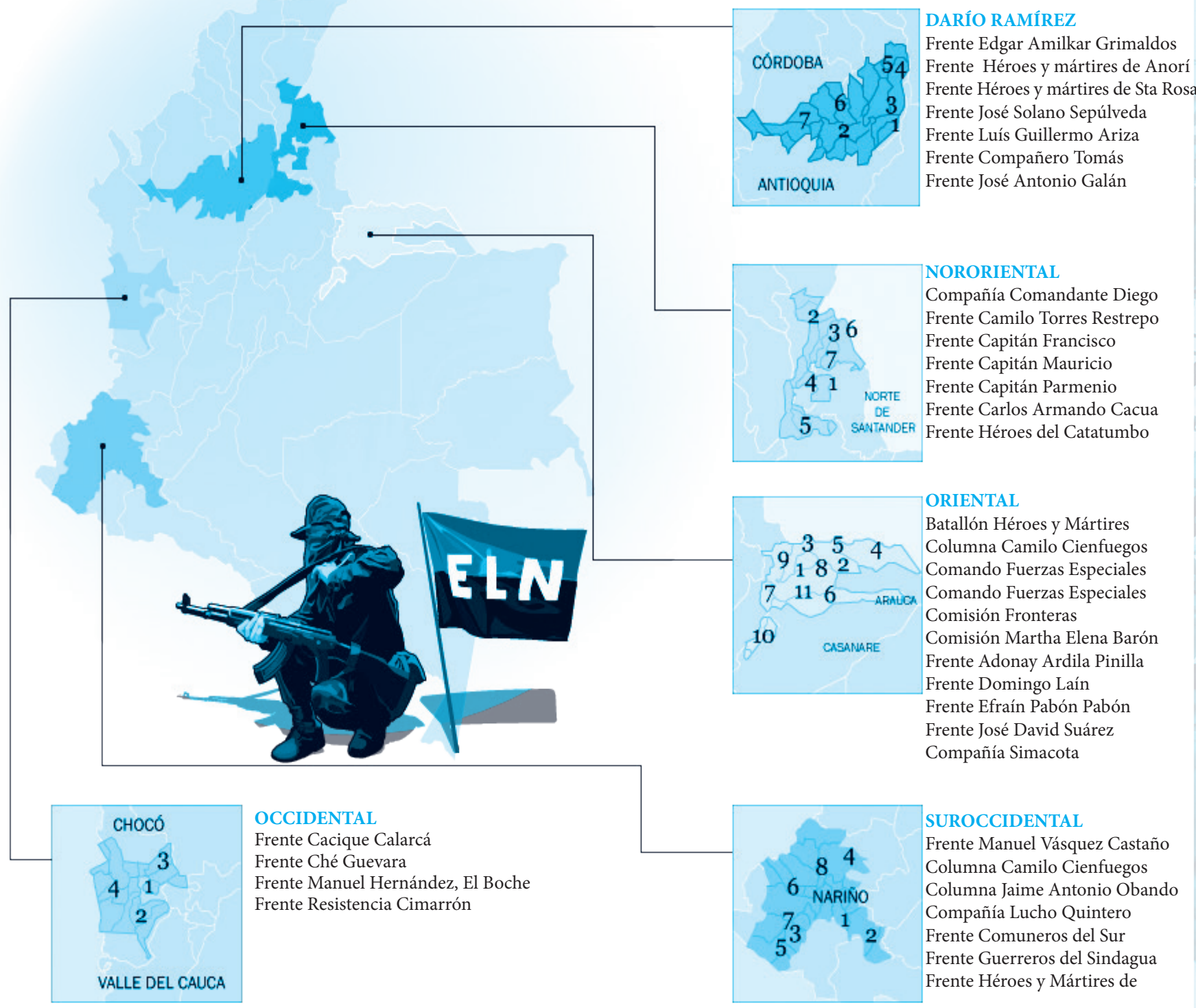

Grafico 1. Tomado de: http://www.semana.com/nacion/multimedialeln-su-poderio-y-su-dificultad-para-negociar/461166 
Hipotético escenario de guerra con el Ejército de Liberación Nacional, ELN.

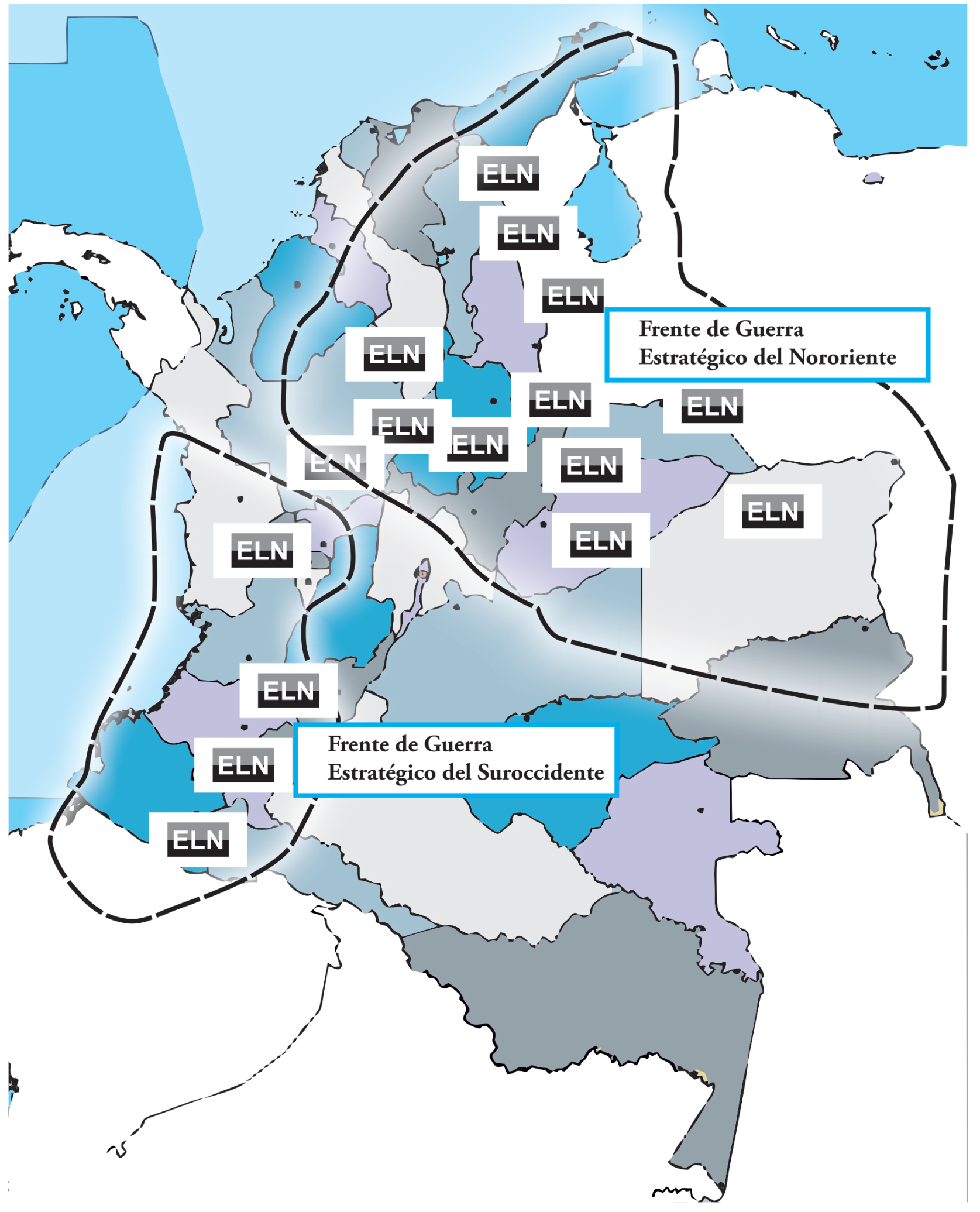

Gráfico 2. Elaboración conceptual del autor de la ponencia. 
Carlos Arturo Velandia Jagua

Una hipótesis de trabajo: termina el conflicto, estalla el posconflicto

Hipotético escenario de guerra con las Fuerzas Patrióticas parar la Salvación Nacional - FPSN

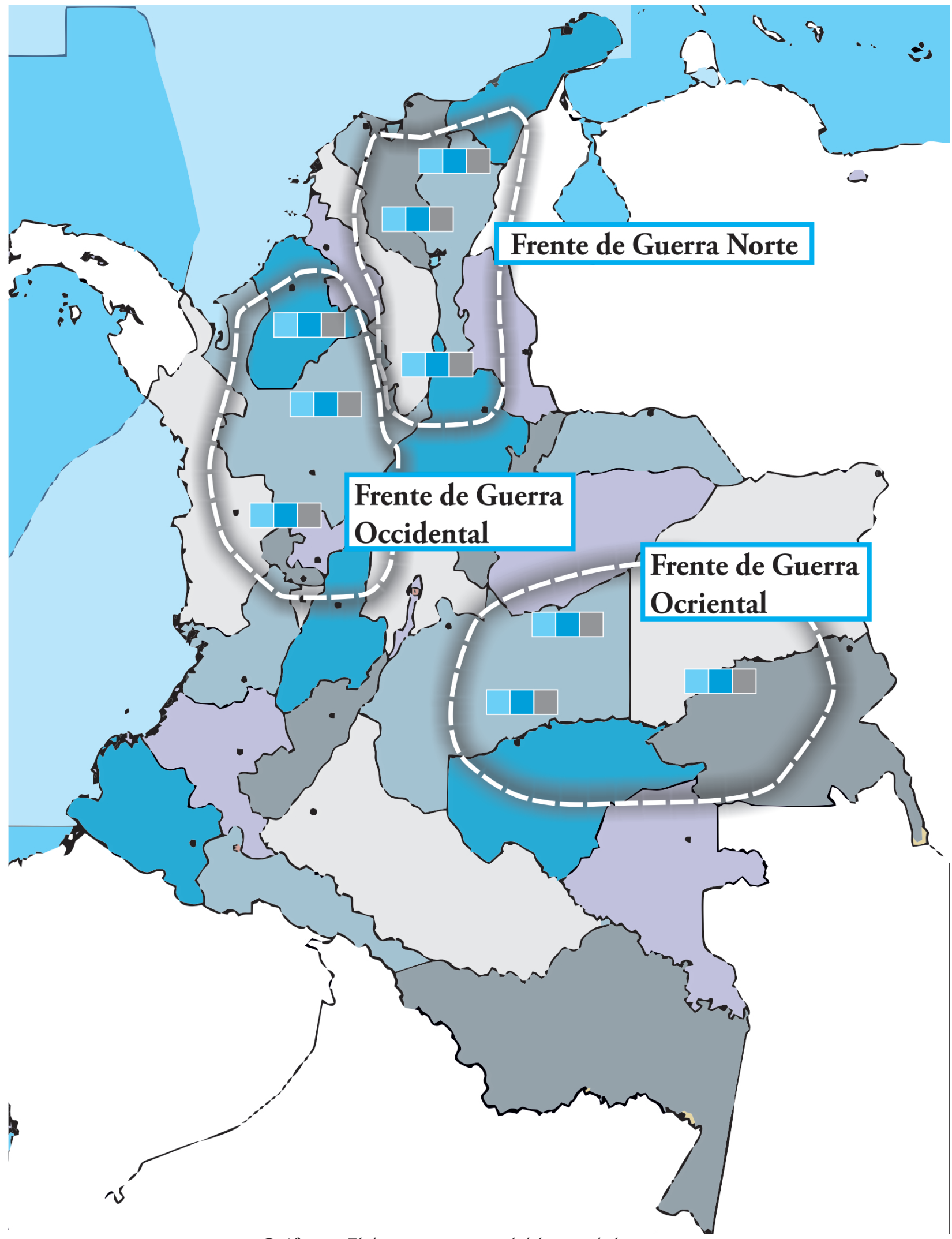

Gráfico 3. Elaboración conceptual del autor de la ponencia. 